private practice by the then Labour government we initially reacted traditionally, each group responding in a slightly different way and with varying degrees of vigour. When, however, we saw that we were failing to convince the government by separate and reasoned argument a meeting was arranged with the then prime minister, Harold Wilson. On the advice of Lord Goodman, one of the shrewdest political minds of this century, it was agreed that all of the presidents of the royal colleges, together with the leaders of the BMA, would attend the meeting but that there would be only one spokesman, who would present the views of the profession as a whole.

During the meeting both the prime minister and the then secretary of state (Barbara Castle) tried to entice individual presidents into the debate and so break the impressive unity of the profession. They failed, and, apart from the usual exchange of courtesies, only one voice spoke for a united profession. The meeting proved to be the turning point in the campaign, and a radically modified and broadly acceptable bill emerged. (The credit for the success of that meeting undoubtedly lay not with the advocate, but with those leaders who gave their solid and silent support.)

By contrast, a recent episode showed the converse of that exercise in collaboration and consensus. When the difficult ethical problem of patient confidentiality during the provision of advice on contraception to minors emerged we saw the unfortunate spectacle of respected colleagues in the General Medical Council and the BMA in apparently open conflict when what was required was careful discussion and consideration of the views and arguments of the other party.

If today the profession could show the same degree of unity as we did over private practice our influence would be appreciably enhanced. If the profession (or, rather, the leaders of the bodies representing the profession) accepted the need for better collaboration and communication then the precise constitutional details would be of secondary importance. Clearly the great institutions would be unwilling to surrender their ultimate independence of thought and action to any supreme body. But the current relatively informal links based largely on occasional and casual meetings have proved inadequate.

The formal liaison between the hospital doctors of the BMA and the presidents of the royal colleges through the Joint Consultants Committee is not perfect, but it shows how independent bodies can work together effectively and harmoniously without losing their independence. A similar arrangement with a reasonably formal machinery, a wider membership, and a wider agenda would undoubtedly be of great value to the profession. It would further strengthen the profession's position if individual bodies and their leaders avoided independent discussions and negotiations with government over issues affecting the whole profession. Though tempting and well intentioned, such independent exercises can and will be used by the government to divide and rule the profession.

The problems facing medicine today demand that our leaders know each other well. They must talk to each other frequently and should understand and take into account the views of other bodies when developing their own policies. Finally, they should do their utmost to present an authoritative and united front on behalf of the profession in the constant battle to maintain professional standards.

TONY GRABHAM Former chairman of council of BMA and of Joint Consultants Committee

General Hospital,

Kettering,

Northamptonshire NN16 8UZ

\title{
Dietary protein and progression of chronic renal disease
}

\section{Large randomised controlled trial suggests no benefit from restriction}

Healthy people rightly consider food for its culinary rather than its biochemical value. With the present state of knowledge, only broad guidelines are appropriate as to what constitutes a healthy diet. In some conditions, however, diet can be critically important to health. This imposes a considerable strain on patients and their families, and maintaining a stringent dietary regimen for a long time is notoriously difficult.

Suggestions from animal studies that restricting dietary protein might slow or abort a steady fall in the glomerular filtration rate aroused much interest in those managing potentially progressive renal disease. ${ }^{12}$ After these early reports several small but disciplined studies of the value of restricting protein intake in humans were published, and these were subjected to a meta-analysis reported in this journal. ${ }^{3}$ The authors concluded that the evidence strongly supported the effectiveness of low protein diets in delaying the onset of end stage renal disease, and the need for a large prospective trial was recognised. Such a trial has now been published 4 ; it found little evidence that rigorous protein restriction slows the progression of renal disease in humans.

The modification of diet in renal diseases study reported that no significant benefit followed dietary intakes of 0.58 $\mathrm{g} / \mathrm{kg}$ body weight in patients with a glomerular filtration rate of $25-55 \mathrm{ml} / \mathrm{min}$ and of $0.28 \mathrm{~g} / \mathrm{kg}$ with ketoacid supplements in patients with a glomerular filtration rate of $13-24 \mathrm{ml} / \mathrm{min}$. In each group the effect of strict control of blood pressure (mean blood pressure $<92 \mathrm{~mm} \mathrm{Hg}$ in patients aged 18 to 60 years at entry and $<98 \mathrm{~mm} \mathrm{Hg}$ in patients aged $\geqslant 61$ at entry) benefits only those patients with at least $1 \mathrm{~g}$ of proteinuria. This suggests that such strict control of blood pressure (achieved principally by inhibition of angiotensin converting enzyme) may affect the course of only some of the diseases causing progressive renal failure.

This large study (with more than 800 patients) is unlikely to be repeated elsewhere. Studies targeted at particular underlying renal diseases or those with a faster fall in glomerular filtration rate than was encountered in the modified diet in renal disease study will, even if mounted successfully, give only partial answers to the overall problem. So doctors will probably have to continue to make pragmatic judgments as to which patients with progressive renal disease, if any, will benefit from protein restriction. 
Animal studies have shown that, in experimentally induced renal impairment, progression to end stage renal failure is accompanied by increased glomerulosclerosis, seemingly precipitated by an increased haemodynamic load on the glomeruli. This in turn stimulates cytokine release from mesangial cells and consequent collagen production.

If a low protein diet is given the cycle is interrupted. Afferent arteriolar dilatation and glomerular haemodynamic stress is much less, and progressive glomerulosclerosis is delayed or absent. Adequate control of blood pressure complements these benefits. As Narins and Cortez point out, the findings of the modified diet in renal disease study do not necessarily conflict with this suggested mechanism. ${ }^{5}$ Possibly the requirements of entry into a long term clinical study, which demand informed and disciplined attention to dietary intake, select out patients already using advice on diet and blood pressure to the limit so that they have already accrued any possible benefit. The slower than predicted fall in glomerular filtration rate in control patients in the modified diet in renal disease study is consistent with such a suggestion. Nevertheless, had there been a decisive benefit from protein restriction a disciplined study such as this would have shown it.

In animal studies benefit has been obtained consistently when dietary intervention occurred immediately after the desired degree of renal impairment had been achieved experimentally. Such early intervention seems impractical in humans. Renal failure occurs relatively silently in many patients, so the public health measures that would be necessary to detect all such patients early enough in their condition to allow months to years of dietary modification are daunting.

For doctors the complex series of variables imposed by underlying renal disease, metabolic and other complications of uraemia, comorbid conditions, and the problems of compliance mean that intervention has to be tailored to each patient. Furthermore, across the world and certainly in both the United States and Britain many patients are first seen by nephrologists when they are at or close to the point of needing dialysis and so are not seen early enough in the course of their disease for dietary intervention to have whatever benefit is possible. Thus the effects of strict dietary control on the number of patients entering renal replacement programmes is likely to be small.

If protein restriction is undertaken then nitrogen and energy intake must be balanced to ensure that nutrition is maintained. Adequate energy intake is at least as important as any other aspect of the diet; modest protein restriction $(0.6 \mathrm{~g}$ of protein $/ \mathrm{kg}$ body weight/day) minimises the overall load of protein products that the kidney must excrete and is a feasible goal. At least one third of the protein should be high in essential amino acids. Once the glomerular filtration rate has reached some $20 \mathrm{ml} / \mathrm{min}$ stricter protein restriction does not seem to confer the benefits in terms of preserving the glomerular filtration rate that animal studies have found; currently the emphasis should be on maintaining nutritional balance and minimising the amount of protein waste product that is produced. Furthermore, modestly reducing the proportion of protein low in essential amino acids seems prudent.

As protein intake is reduced so is the intake of phosphates; these are excreted mainly through the kidney, so the rise in plasma phosphate concentration is minimised. This has benefits in terms of ensuring that calcium phosphate is not laid down in crystallised form in body tissues and may also reduce secretion of parathyroid hormone.

Because some lipid subfractions may damage the glomerulus directly, dietary control of lipid intake may turn out to be important. (This is currently being researched.) If so, dietary intervention may yet prove to be a valuable tool in changing the rate at which renal function falls in progressive disease; its place in halting such a fall is much less certain.

N P MALLICK

Manchester Royal Infirmary, Professor of renal medicine

Manchester M13 9WL

1 Klahr S, Schreiner G, Ichikawa I. The progression of renal disease. $N$ Engl $\mathcal{f}$ Med 1988;318:1657-66.

2 Brenner BM. Nephron adaptation to renal injury or ablation. Am f Physiol 1985;249:F324-37. 3 Fouque D, Laville M, Boissel JP, Chifflet R, Labeeuw M, Zech PY. Controlled low protein diets in chronic renal insufficiency: meta-analysis. $B M F$ 1992;304:216-20.

$4 \mathrm{~K}$ har S, Andrew S, Levey MD, Beck GJ, Caggiula W, Hunsicker $L$, et al. The effects of dietary protein restriction and blood pressure control on the progression of chronic renal disease. $N$ protein restriction and blood p
Engl $f$ Med 1994;330:877-84.

5 Narins RG, Cortes P. The role of dietary protein restriction in progressive azotemia. $N$ Engl $f$ Med 1994;330:929-30.

\section{The new measles campaign}

\section{Immunisation should prevent an epidemic predicted by modelling}

The national measles and rubella campaign that begins next month is one of the most ambitious vaccination initiatives that Britain has undertaken. The aim is to vaccinate $95 \%$ of the seven million schoolchildren aged between 5 and 16 within one month and so to prevent an epidemic of measles that would otherwise be likely to occur early next year. ${ }^{12}$ The novel feature of this campaign is that it is meant to prevent an epidemic: the more usual response is to wait for an outbreak to occur before doing anything. This preventive action is likely to be far more cost effective than attempts to curtail spread once the chains of transmission are established. Experience in North America has shown that, despite the adoption of prompt and aggressive measures to control outbreaks, transmission is rarely interrupted. ${ }^{34}$
The campaign is based on comprehensive epidemiological surveillance data including serological studies, number of cases notified and confirmed, rates of complications and deaths, and immunisation coverage. ${ }^{2} 56$ These data have been used in two independent mathematical models: both have predicted a high probability of a major resurgence of measles, with the greatest burden of cases in children in secondary schools and a considerable number in children in primary schools. ${ }^{1}$

The Department of Health is convinced that the cost of preventing such an epidemic through a mass campaign will be considerably less than the direct and indirect costs of the predicted epidemic. By including rubella vaccine the campaign is expected to hasten the elimination of the congenital rubella syndrome by reducing the pool of 